\title{
Learning Scenario to Promote Comprehension of the Meaning of Subtraction
}

\author{
Ricardo Silva ${ }^{1,2,3, *} \mathbb{0}$, Fernando Martins ${ }^{3,4} \oplus$, Cecília Costa ${ }^{1,2} \oplus$, José Cravino ${ }^{1,2}(\mathbb{C}$ \\ and Joaquim Bernardino Lopes ${ }^{1,2} \mathbb{C}$
}

1 Escola de Ciências e Tecnologia, Universidade de Trás-os-Montes e Alto Douro, 5000-801 Vila Real, Portugal; mcosta@utad.pt (C.C.); jcravino@utad.pt (J.C.); blopes@utad.pt (J.B.L.)

2 CIDTFF-Centro de Investigação em Didática e Tecnologia na Formação de Formadores, Universidade de Aveiro, 3810-193 Aveiro, Portugal

3 Instituto Politécnico de Coimbra, ESEC, NIEFI-PEAPEA, 3030-329 Coimbra, Portugal; fmlmartins@esec.pt

4 Instituto de Telecomunicações, Delegação da Covilhã, 6201-001 Covilhã, Portugal

* Correspondence: rjpsilva@esec.pt

Citation: Silva, R.; Martins, F.; Costa, C.; Cravino, J.; Lopes, J.B. Learning Scenario to Promote Comprehension of the Meaning of Subtraction. Educ. Sci. 2021, 11, 757. https://doi.org /10.3390/educsci11120757

Academic Editors: Pedro José

Arrifano Tadeu, Inmaculada

García-Martínez and Mehmet Kaya

Received: 13 October 2021

Accepted: 18 November 2021

Published: 23 November 2021

Publisher's Note: MDPI stays neutral with regard to jurisdictional claims in published maps and institutional affiliations.

Copyright: () 2021 by the authors. Licensee MDPI, Basel, Switzerland. This article is an open access article distributed under the terms and conditions of the Creative Commons Attribution (CC BY) license (https:// creativecommons.org/licenses/by/ $4.0 /)$.

\begin{abstract}
The integration of virtual manipulatives in classroom practices facilitates student learning processes. For this, the teacher must understand how to support students in establishing mathematical connections between the manipulation and their interpretations of the representations. We present a learning scenario that integrates the use of virtual manipulatives in mathematical modelling tasks. It was designed and implemented during initial teacher training, with the aim of helping a group of first-year elementary school students to overcome difficulties identified in their comprehension of the meaning of subtraction. The research, following the principles of design-based research, included three distinct moments: an individual written pre-test, an intervention phase with six micro-cycles, and an individual written post-test. The analysis of the collected data-audio, screen recordings, and written productions-allowed us to identify the most influential structural characteristics of the learning scenario: mathematical communication, collaborative learning, self-regulation, and co-regulation of learning. Our results suggest that differentiated instruction, minimal guidance, and scaffolding played an important role in the support provided by the pre-service teacher to students in the mathematical modelling activities that integrated virtual manipulatives.
\end{abstract}

Keywords: pre-service teacher; virtual manipulatives; mathematical modelling; elementary mathematics; subtraction; learning scenarios

\section{Introduction}

The constraints imposed by the COVID-19 pandemic in Portugal caused an exponential increase in the use of technology in teaching and learning processes, even among teachers who have always been reluctant [1]. The importance of digital technologies in education systems is undeniable [2], reinforced by the emergence of digital natives [3] and the way they perceive it. It is important to discuss how technology can be used to benefit learning [4]. Not only does it change the way of teaching but it also affects what can be taught, while providing opportunities for students to interact with mathematical ideas [5] by allowing manipulation and visualisation of mathematical concepts [4]. The role of the teacher in integrating technology is central and crucial. This requires teachers to possess a set of skills that allow them to choose, adapt, or create pedagogical resources suitable to the learning objectives [6]. For the integration of technology in teaching processes to be properly achieved, it should stem from the context and serve the learning objectives [7].

Appropriate integration of technology in mathematics education rests on three pillars: didactic design, teacher performance, and educational context [8]. It is not enough for teachers to be competent in handling technological tools, they need to be able to mobilize specialized knowledge to create conditions that promote mathematical learning [4]. It 
is therefore increasingly important to prepare future teachers to develop and articulate their pedagogical, technological, and content knowledge in practical and contextualized situations [9], allowing them to develop skills necessary to create learning scenarios that promote an appropriate integration of technology [10].

A learning scenario is a teaching and learning situation (fictional or anchored in reality) that describes the context in which learning occurs, based on its constituent elements: organizational design of the environment; roles and objectives of the actors; storyline, work strategy, performances, and proposals; and reflection and regulation [11]. The design and implementation of learning scenarios have an intrinsic reflective nature, which promotes an understanding of the implications of the decisions made [12]. This practice contributes to the professional development of pre-service teachers (PST), in a cycle of expansive learning [10] (Figure 1).

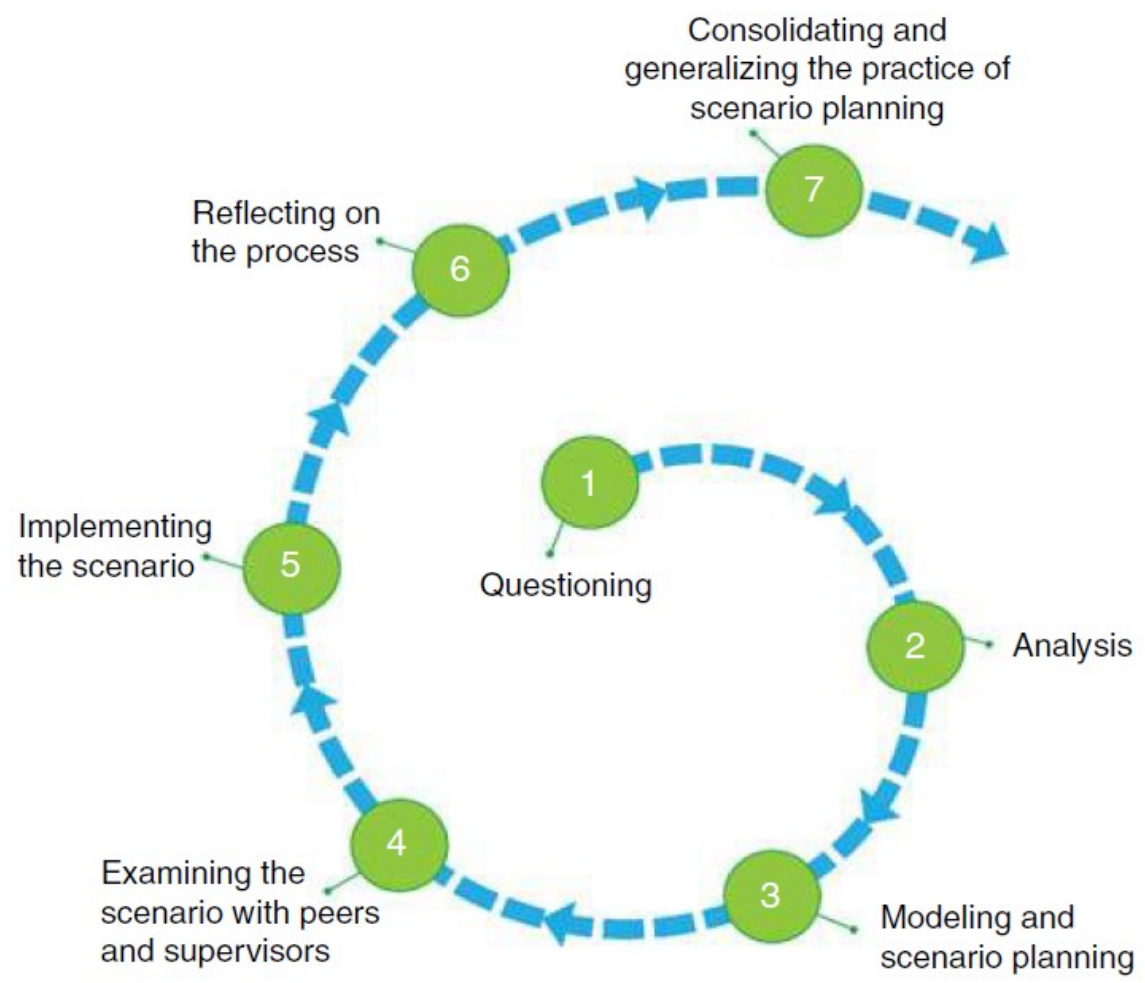

Figure 1. The cycle of expansive learning [10].

This article reports on the period of training of elementary school teachers-with a class of first-year elementary school students-during which difficulties in comprehending the meanings of subtraction by the students were identified. With the purpose of helping them to overcome the identified difficulties, the learning scenario presented in Section 2.2. was designed and implemented. Appropriate solutions for the class context were sought in the literature, with particular attention to reading and writing skills, as well as to the group routines.

When preparing teaching sequences for subtraction, a learning trajectory and the students' competencies necessary to understand and make use of the mathematical concepts involved should be taken into account [13]. The positive contribution of word problems to learning subtraction $[14,15]$ and of representations, including manipulatives, whether concrete or virtual, is also recognised [16]. The use of computational tools to solve tasks should be done in such a way that teaching strategies promote comprehension of the mathematical concepts involved [17].

A well-established tool in mathematics education, virtual manipulatives (VM) [18], has evolved considerably in recent years [18]. In this study, we adopted the definition proposed by Moyer-Packenham and Bolyard: "An interactive, technology-enabled visual representation of a dynamic mathematical object, including all of the programmable 
features that allow it to be manipulated, that presents opportunities for constructing mathematical knowledge" ([18]). Its application in the classroom is no guarantee of learning. The teacher must be a mediator of mathematical meanings [19], helping students to establish connections between the manipulation and mathematical concepts [20].

The use of VM allows students to test and validate hypotheses on-screen without fear of negative feedback from peers or teachers; this experimentation can encourage students to establish connections between concepts and virtual representations [21]. The teacher can take advantage of these features to help students overcome obstacles by using teacher scaffolding [20]. VM allow visualisation and reduce abstraction, thus making mathematical concepts more understandable [22,23].

The selection of VM to be used should be careful and aligned with the learning objectives, according to their affordances and constraints, so that their integration into the teaching and learning processes may contribute to the comprehension of mathematical concepts [24]. Shih [25], in her case study, reports the positive contribution of VM to students' ability to correct misconceptions related to subtraction.

The integration of computational tools in the classroom, using mathematical modelling (MM) as a learning environment, helps students to make multiple mathematical connections, fostering the development of mathematical comprehension [26] and its concepts. Although different perspectives on MM exist, there is a consensus that it is a two-way translation process between the real world and mathematics [27]. It is cognitively demanding since it operationalizes mathematical and non-mathematical skills and knowledge [28]. When using MM as a learning environment, the teacher should seek a balance between minimal teacher guidance and maximal student independence [29]. Supported by the diagnostic assessment of students' mathematical knowledge, scaffolding strategies [29] can be applied to help students make connections between mathematical and non-mathematical knowledge [27]. In addition to representing the interaction between formal mathematics and reality, word problems are often the only means of providing students with opportunities to experience the basic principles of mathematisation and MM [30]. By starting from real-world problems, $\mathrm{MM}$ as a learning environment is conducive to the construction of meaningful learning, promoting the active participation of students [28].

The present study expands on previous work [31-34] dedicated to understanding how the integration of virtual manipulatives in classroom practices, using MM as a learning environment, generated positive impacts on students' construction of mathematical knowledge. It was already established that the intervention contributed to improvements in participating students' comprehension of the meanings of subtraction [31].

Regarding integration of VM in classroom practices, there is already a body of studies about the teacher's feedback that allow students to be able to use these tools and complete a task. However, the discussion is still in its early stages on how the teacher should support students to make mathematical connections between the manipulation and their interpretations of the representations [35]. It is important to understand not only the characteristics of the teacher's performance but also what influential relationships exist between the actions of the teacher and the students.

Thus, two research questions were established: (1) which characteristics of the learning scenario contributed to the students' comprehension of the meanings of subtraction, and (2) what relationships exist between the constituent elements of the learning scenario? The search for answers to these research questions was based on the analysis of a mapping of constituent elements of the learning scenario and their relationships throughout the action units [36]. Structural characteristics of the learning scenario were identified related to mathematical communication [37]; collaborative learning [38]; and self-regulation and co-regulation of learning [39]. These identified characteristics are strongly aligned with how $\mathrm{MM}$ was integrated into the learning scenario, taking advantage of the affordances and constraints of the chosen VM. 


\section{Materials and Methods}

Taking into account the objectives and research questions of the study, the chosen methodology followed the principles of design-based research [40] considering each of the sessions of the intervention phase (Section 2.1.3) as a micro-cycle. A didactic sequence was designed, grounded on the Technological Pedagogical Content Knowledge (TPACK) conceptual model [7] and the students' context.

\subsection{The Learning Scenario}

The constituent elements of the learning scenario are presented below, following the proposal of Matos [11].

\subsubsection{Organisational Design of the Environment}

The present study took place in the 2017/2018 school year, during the practice component of PST training, with a first-year elementary school class in a school in the city of Coimbra (central area of Portugal). Difficulties in the resolution of tasks related to the meanings of addition and subtraction by the students were identified [31], including recognition of the presence of the meaning of subtraction in word problems, understanding the meaning of quantities present in word problems, relating the quantities present in word problems with the strategies chosen to solve them (bead-line and number line representation), and relating quantities present in word problems with the meaning they assume in the arithmetic operation subtraction (minuend, subtrahend, and difference).

To find solutions that would allow students to fill gaps in their mathematical knowledge, a didactic sequence was designed, based on the curricular guidelines, seeking to give an active role to students and to integrate technology adequately in the teaching and learning processes [41]. For this purpose, tasks created were grounded on the TPACK conceptual model, supported by the integration of VM in classroom practice and using $\mathrm{MM}$ as a learning environment. The choice of MM as a learning environment and VM as a technological artifact was based on two factors: they have been discussed in the PST training, which facilitated the design of the scenario and its discussion with the supervisors; according to the literature review, their characteristics serve the established learning objectives and are suitable to the classroom context.

The option to use VM was reinforced by the fact that the use of computational tools was part of the class routines - especially the interactive whiteboard and word processorproving to be a motivating factor for involvement in the tasks. Two VM were chosen according to the following requirements: they should limit the value of numbers to quantities already known to the students, and they should prompt the use of appropriate mathematical terms in students' discourse, taking advantage of the affordances and constraints of the VM [24]. For the sessions dedicated to the meanings of compare and complete, it was also considered necessary that the VM reinforces the importance of rigorous construction of the number line. For the session dedicated to the meaning of remove, the chosen VM was Base Blocks Subtraction, from the repository of the National Library of Virtual Manipulatives (http://nlvm.usu.edu/, 22 November 2021). For the sessions dedicated to the meaning of compare and complete a $\mathrm{V}$, a structured number line (https:/ / www.geogebra.org/m/scwjXjee, 22 November 2021) was created by the research team in GeoGebra [34], given that a freeware solution existing in Portuguese that met the established criteria was not found.

In addition to students' written productions, students' interactions with each other, with the PST, and with the VM were also collected through screen-recordings. The use of video recordings allows the PST to access students' interactions and cognitive processes, becoming a reflective tool, not only of teaching performance but of the didactic intervention [42].

Informed consent was obtained from all participants by a form that was delivered to children's legal guardians. Data protection was assured by following the institutional 
protocol in place that regulates the practice component of PST training, including data collection procedures.

\subsubsection{Roles and Actors}

The PST teaching practice (more details about this PST teaching practice can be found in our previous work [34]) included differentiated instruction, providing support for students' autonomous work with minimal teacher guidance, while helping them to establish connections between mathematical concepts and the manipulation of the applets.

The 26 students of the class were grouped into 13 pairs. The pair formation followed the conditions of the Zone of Proximal Development (ZPD) [43], using the results of the students' individual written tasks in the initial phase (Section 2.1.3). These were analysed according to the task analysis criteria created by the research team (Table 1), thus establishing the levels of optimal discrepancy.

Table 1. Task analysis criteria.

\begin{tabular}{|c|c|c|c|}
\hline & Level 1 & Level 2 & Level 3 \\
\hline $\begin{array}{l}\text { Mathematical } \\
\text { concepts }\end{array}$ & $\begin{array}{l}\text { The explanation shows } \\
\text { very limited knowledge } \\
\text { of the mathematical } \\
\text { concepts used to solve } \\
\text { the task or does not give } \\
\text { an explanation. }\end{array}$ & $\begin{array}{l}\text { The explanation } \\
\text { shows some } \\
\text { comprehension of the } \\
\text { mathematical } \\
\text { concepts used to } \\
\text { solve the task but } \\
\text { lacks coherence or } \\
\text { logic or contains } \\
\text { some erroneous } \\
\text { acceptances. }\end{array}$ & $\begin{array}{l}\text { The explanation } \\
\text { demonstrates a } \\
\text { complete } \\
\text { comprehension of the } \\
\text { mathematical } \\
\text { concepts used to } \\
\text { solve the task. }\end{array}$ \\
\hline
\end{tabular}

Although the whole class participated, this article discusses the results of two student pairs, considered representative for including the three levels of optimal discrepancy considered. The first group was formed by a student at level 1 and a student at level 2, and the second group was formed by a student at level 2 and a student at level 3 . The characteristics of the learning scenario introduced in the next section were included in the study design in order to give the students a high degree of autonomy as well as creating conditions for self-regulation and co-regulation of students' mathematical learning.

\subsubsection{Plot, Working Strategies, Performances, and Proposals}

To carry out this study, several steps were taken (Table 2).

Table 2. Schedule of the study phases.

\begin{tabular}{|c|c|c|c|c|c|c|c|}
\hline \multirow{3}{*}{$\begin{array}{l}\text { Initial Phase } \\
12 \text { February }\end{array}$} & \multicolumn{6}{|c|}{ Intervention Phase } & \multirow{3}{*}{$\begin{array}{c}\text { Final Phase } \\
\text { 2 June }\end{array}$} \\
\hline & \multirow{2}{*}{$\begin{array}{c}\text { VM } \\
\text { Exploration }\end{array}$} & \multicolumn{5}{|c|}{ Meanings of Addition and Subtraction } & \\
\hline & & Add & Remove & Complete & Compare & Join & \\
\hline & 12 April & 26 April & 3 May & 10 May & 17 May & 31 May & \\
\hline
\end{tabular}

The initial phase involved a set of word problems, solved individually by the students, relating to the meanings of each of the operations of addition (join and add) and subtraction (remove, compare, and complete). Their analysis allowed mapping the students' difficulties, seeking improvements in the didactic sequence design and forming pairs according to the ZPD conditions.

The intervention phase included six sessions guided by the principles of computersupported collaborative learning (CSCL) [44]. Supported by MM as a learning environment in which VMs were used, they took place in the school library, with one computer for each pair of students. In the first session (VM exploration), the students explored the 
VMs so that they could be a positive contribution rather than an obstacle to the learning process. Each of the meanings of addition and subtraction were covered in the following sessions. The tasks created for each session followed the principles of authentic learning and authentic tasks identified by Herrington et al. [45]. These were solved by pairs with the collaboration of the teacher, who sought to help students make mathematical connections between the manipulation and the concepts involved through dialogue and questioning. The task implementation and solutions found were discussed at the end of each session.

The final phase, which was identical to the initial phase, had a new set of word problems. The analysis of the students' results allowed comparison with those of the initial phase and thus also to draw conclusions about improvements in the students' comprehension of the meanings of addition and subtraction.

\subsubsection{Reflection and Regulation}

The data from different sources collected in each session of the intervention phase (Section 2.2) were analysed before the following session to identify improvements to be implemented in the next sessions or the need to redesign them.

\subsection{Procedures}

The procedures for the sessions dedicated to meanings of subtraction are described in the present study, while the sessions dedicated to addition can be found in another publication [33].

Data was collected using different sources: students' written productions, participant observation, field notes, audio, and screen recordings captured with FlashBack Express Recorder software.

The data collected through screen recordings and audio recordings were subjected to content analysis, supported by the MAXQDA software [46], seeking to map action units [36]. To this end, a set of categories was created within two dimensions [36]: roles and actors (Table 3 ) and plot, working strategies, performances, and proposals (Table 4), corresponding to the constituent elements of the established learning scenario.

Table 3. Framework of analysis; dimension of roles and actors.

\begin{tabular}{|c|c|}
\hline Categories & Definition and Codes \\
\hline $\begin{array}{l}\text { Differentiated } \\
\text { instruction (DI) }\end{array}$ & $\begin{array}{l}\text { - Teacher actions that encourage the student to take an active role in } \\
\text { the learning process, drawing on their skills and ideas (DI1). } \\
\text { - Teacher actions, based on knowledge of the characteristics of } \\
\text { students and the class that enable teaching strategies to be adjusted } \\
\text { to the group and/or individual (DI2). }\end{array}$ \\
\hline $\begin{array}{l}\text { Minimal guidance } \\
\qquad(\mathrm{MG})\end{array}$ & $\begin{array}{l}\text { - Teacher actions that promote student autonomy, offering the } \\
\text { necessary support and minimising teacher intervention. } \\
\text { - } \quad \text { Support requested by students (MG1). } \\
\text { - Support at the initiative of the PST (MG2). }\end{array}$ \\
\hline Scaffolding $(S)$ & $\begin{array}{l}\text { Teacher actions that provide temporary and adjusted support for } \\
\text { students, enabling them to complete tasks they would not otherwise } \\
\text { be able to. } \\
\text { - Planned (S1). } \\
\text { - Spontaneous (S2). }\end{array}$ \\
\hline $\begin{array}{c}\text { Mathematical } \\
\text { connections (MC) }\end{array}$ & $\begin{array}{l}\text { PST actions that help students establish connections between the VM } \\
\text { manipulation and the mathematical concepts involved. }\end{array}$ \\
\hline
\end{tabular}


Table 3. Cont.

\begin{tabular}{ll}
\hline \multicolumn{1}{c}{ Categories } & \multicolumn{1}{c}{ Definition and Codes } \\
\hline $\begin{array}{l}\text { Collaborative } \\
\text { learning (CL) }\end{array}$ & $\begin{array}{l}\text { Interactions between PST and students (CL1) and between students } \\
\text { (CL2) that enable them to find solutions, create a product, and seek to } \\
\text { understand meanings or concepts. }\end{array}$ \\
\hline $\begin{array}{l}\text { Self-regulated } \\
\text { learning (SR) }\end{array}$ & $\begin{array}{l}\text { Intentional actions by the learner in which he/she regulates his/her } \\
\text { behaviour, motivation, emotions, and cognitive process to achieve } \\
\text { learning. }\end{array}$ \\
\hline $\begin{array}{l}\text { Co-regulation of } \\
\text { learning (CR) }\end{array}$ & $\begin{array}{l}\text { Interactions between PST and students (CR1) and between students } \\
\text { (CR2) that promote the regulation of behaviour, motivation, } \\
\text { emotions, and cognitive process to achieve learning. }\end{array}$ \\
\hline
\end{tabular}

Table 4. Framework of analysis, dimension plot, working strategies, performances, and proposals.

\begin{tabular}{|c|c|}
\hline Categories & Definition and Codes \\
\hline $\begin{array}{c}\text { Virtual } \\
\text { manipulatives } \\
\text { (VM) }\end{array}$ & $\begin{array}{l}\text { - Interactions with VM that provide } \\
\text { - } \quad \text { Immediate feedback (VM1). } \\
\text { - } \quad \text { Allow visualisation of mathematical concepts (VM2). } \\
\text { - Create opportunities for the teacher to help students make } \\
\text { connections between the VM manipulation and the mathematical } \\
\text { concepts involved (VM3). } \\
\text { - Opportunities to pose and test hypotheses (VM4). }\end{array}$ \\
\hline $\begin{array}{l}\text { Mathematical } \\
\text { modelling (MM) }\end{array}$ & $\begin{array}{l}\text { - Student interactions that are representative of collaborative work } \\
\text { (MM1). } \\
\text { - } \quad \text { Evidence of students' mathematical communication (MM2). } \\
\text { - Student actions that establish connections between mathematical } \\
\text { concepts/knowledge and reality (MM3). } \\
\text { - Evidence that students solve a real problem through a mathematical } \\
\text { description (MM4). }\end{array}$ \\
\hline
\end{tabular}

The data collected were analysed to identify the frequency of these elements and their proximity and co-occurrence relations. Proximity occurrences are those that occur within the same action unit or in two sequential action units, and co-occurrences are those that occur simultaneously in the same action unit. Based on these criteria, it was possible to obtain graphs of proximity relations (Section 3.2) and co-occurrence (Section 3.3) between elements of the learning scenario.

\section{Findings}

The results are presented regarding the mapping of the constituent elements of the learning scenario along with its implementation. First, we present their relative frequency (Section 3.1), then relationships are identified between the occurrences concerning their proximity (Section 3.2) and co-occurrence (Section 3.3).

\subsection{Frequency of the Learning Scenario Elements}

The frequency distribution of the learning scenario elements is summarised in the figure below (Figure 2). The analysis of the collected data (Table A1), according to the categories proposed in Table 4, allowed the identification of the presence of all categories foreseen for the roles and actors (RA) dimension and most of the respective codes. No 
occurrence was identified of differentiated instruction concerning the teacher's actions that encourage the student to assume an active role in the learning process (DI1) nor of planned scaffolding (S1). With regard to the dimension of plot, working strategies, performances, and proposals (PWsPP), the occurrence of all categories and codes was identified.

In the RA dimension, it was possible to observe a higher incidence of actions associated with the students' expected role. This pattern is particularly visible in the students' interactions related to collaborative learning (CL2), co-regulated learning (CR2), and selfregulated learning (SR). Regarding the PST role, it is noticeable that PST/student interaction frequency was significantly lower than the frequency of interactions between students.

Looking at the PWsPP dimension, within the VM category, the highest number of occurrences refers to VM allowing visualising mathematical concepts (VM2). Within the MM category, the results indicate a higher frequency of situations related to pair work (MM1 and MM2). The evidence of students' mathematical communication (MM2) had the absolute highest value of all situations, considerably exceeding the number of situations mapped to interactions with VMs that allowed visualising mathematical concepts (VM2), whose frequency corresponded to the second-highest value. On the other hand, situations related to students being able to establish connections between mathematical concepts and reality (MM3) had the lowest frequency in the MM category.

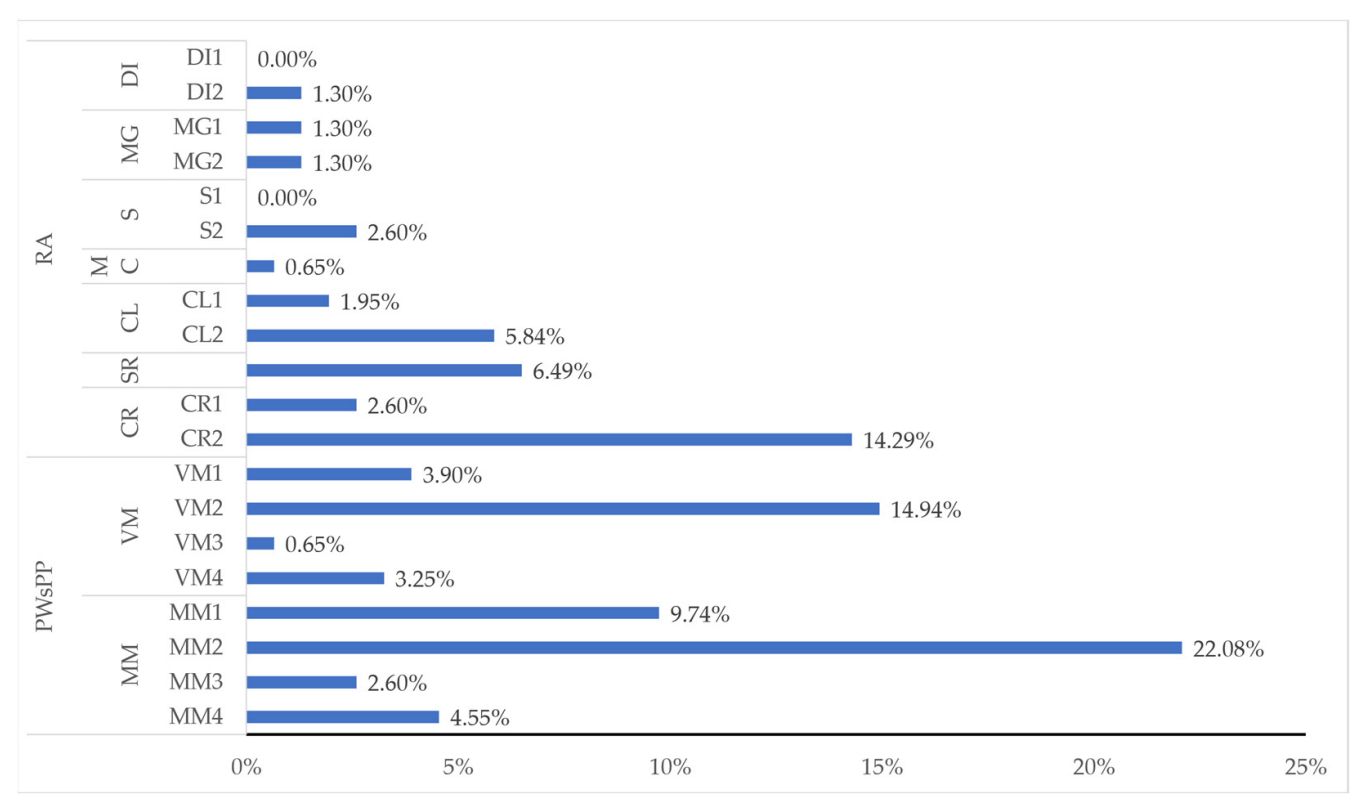

Figure 2. Frequency distribution of the elements of the learning scenario, according to the framework of analysis (Table 3).

\subsection{Proximity between Elements of the Learning Scenario}

The proximity between elements of the learning scenario is represented in the graph below (Figure 3), generated with the values presented in Table A2, providing visual support for proximity relations found. The dimension of the nodes is directly proportional to the frequency of the codes found in the action units, whereas the thickness of the lines is representative of the number of relations between codes identified. From its interpretation, the most common patterns in the proximity relations between elements of the learning scenario stand out.

It is possible to identify a web of influences involving the codes MM1, MM2, MM4, CR2, VM2, and CL2. Consistent with the frequency mapping in the previous section, students' mathematical communication (MM2), interactions between students that promote co-regulation of learning (CR2), and their interactions with VMs that allow visualising mathematical concepts (VM2) are a reiterated occurrence in the vicinity of most elements of the learning scenario. 
It is considered relevant to point out the proximity relations of situations related to co-regulation of learning among students (CR2) and between teacher and students (CR1), spontaneous scaffolding (S2), and self-regulation of learning (SR). A relevant pattern is also identified in the proximity relations between students' co-regulation of learning (CR2) and the virtual manipulatives category (VM1, VM2, VM3, and VM4).

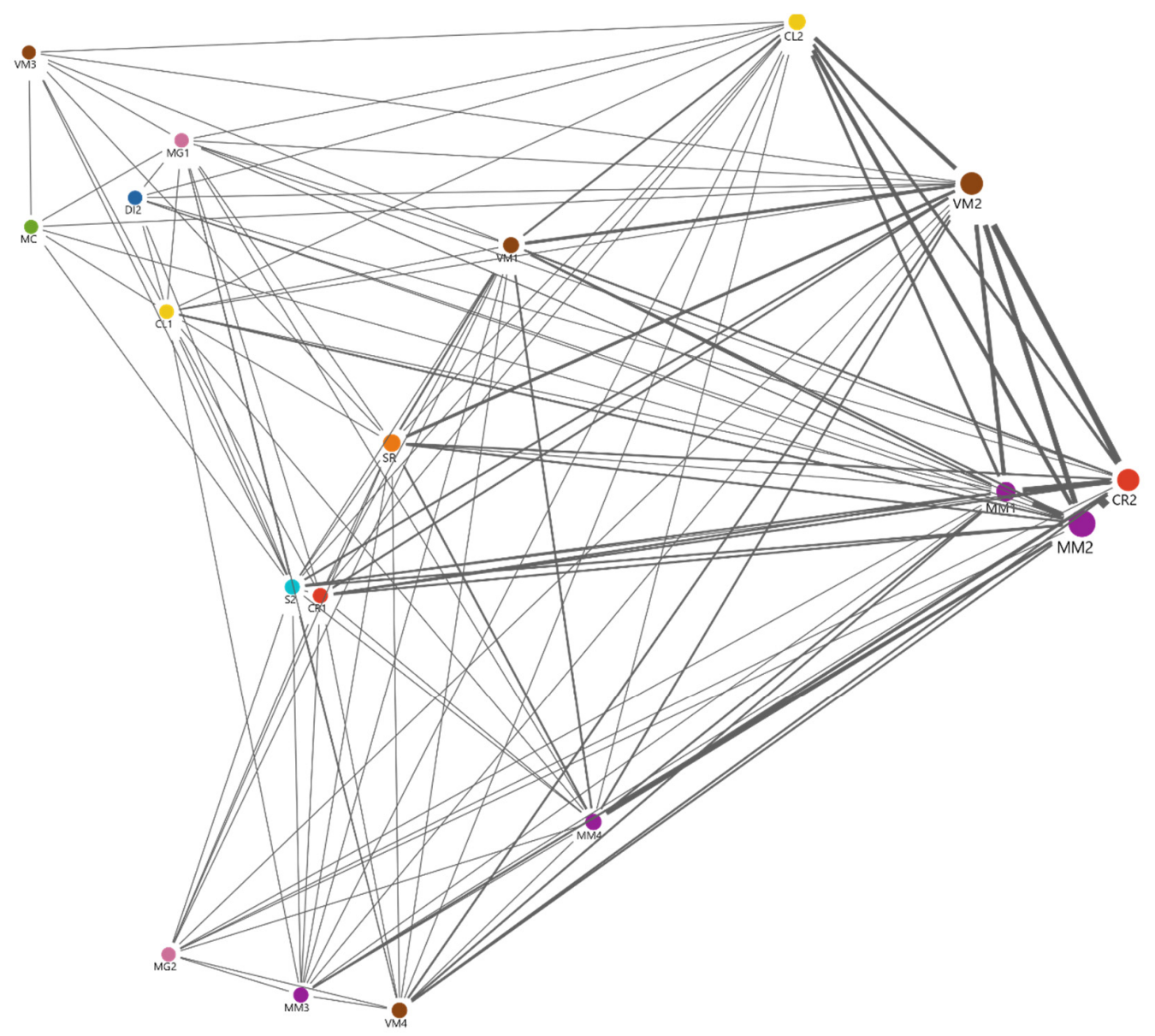

Figure 3. Proximity relation between elements of the learning scenario.

\subsection{Co-Occurrence of Elements of the Learning Scenario}

This section is dedicated to the presentation of results related to the co-occurrence of elements of the learning scenario, synthesized in the graph of the figure below (Figure 4), generated with the values shown in Table A3, providing visual support for the co-occurrences found. The dimensions of the nodes are directly proportional to the frequency of the codes found in the action units, whereas the thickness of the lines is representative of the number of relations between codes identified. The results of the co-occurrence of learning scenario elements reinforce the preponderance of mathematical communication among students (MM2).

It is possible to identify a pattern of simultaneous occurrences of the codes included in the mathematical modelling category (MM1, MM2, MM3, and MM4). A pattern of co-occurrence is also visible among situations involving mathematical communication (MM2), collaborative work (MM1), self-regulation of learning among students (CR2), and collaborative learning (CL2).

Mathematical communication (MM2) is also associated with situations in which students establish connections between mathematical concepts and knowledge and reality (MM3), solve a real problem through a mathematical description (MM4), and collaborative learning situations involving the PST and students (CL1). Although less frequent than the relations pointed out above, the co-occurrence of situations in which the manipulation of 
VMs allowed visualising mathematical concepts (VM2) with students' collaborative work (MM1), their collaborative learning (CL2), and in which they co-regulate their learning (CR2) is also noteworthy.

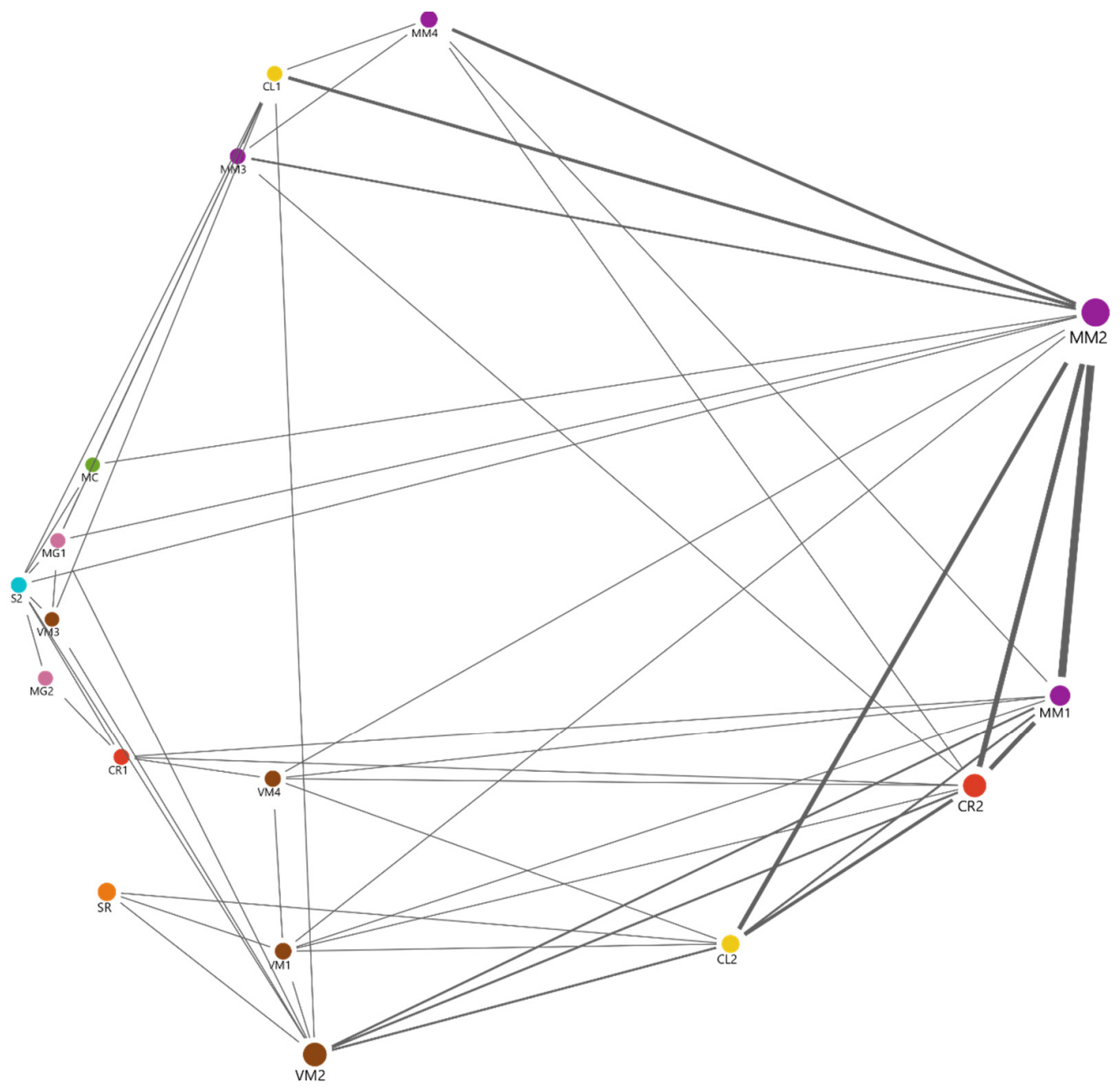

Figure 4. Co-occurrence of elements of the learning scenario.

\section{Discussion}

This study reports on a specific context. The PST skills are still at an early stage of development; the didactic sequence presented in this learning scenario was implemented only once; and the results refer to two pairs of students. Given these constraints, contributions are offered to discuss the structuring elements of the learning scenario that contributed to promoting students' comprehension of the meanings of subtraction. Also discussed are the influential relationships existing between the roles intended for the PST and for the students in tasks that integrate VM, using MM as a learning environment. Mathematical communication, self-regulation, and co-regulation of learning and collaborative learning appear to be related to the integration of VM throughout the learning scenario. There is evidence to suggest that differentiated instruction, minimal guidance, and scaffolding may have contributed to students being able to establish mathematical connections between the manipulation and their interpretations of the representations offered by the VMs.

Answering the first research question (which characteristics of the learning scenario contributed to the students' comprehension of the meanings of subtraction?), mathematical communication, collaborative learning, self-regulation, and co-regulation of learning are considered to be the characteristics of the learning scenario with the greatest influence on its structure. 
By including MM and VM in the design of the learning scenario, we sought a minimalist intervention by the PST, creating conditions that would promote students' autonomous work [29], taking advantage of the affordances and constraints of VMs so that mathematical concepts would be correctly reinforced $[24,47]$. This design choice is validated by the results presented, where there is a higher frequency of elements of the learning scenario in the RA dimension related to the students' role (CL2, CR2, and SR) as opposed to the idealised role for the teacher (DI, MG, S, CL1, and CR1).

The frequency of elements of the learning scenario included in the PWsPP dimension corroborates the importance of immediate feedback (VM1) from VMs, identified by Durmuş and Karakirik [47], as well as allowing students to visualize mathematical concepts (VM2) [22,23] and pose and test hypotheses (VM4) [20]. These results are considered to support the argument that the characteristics of the proposed learning scenario contributed to the promotion of student autonomy.

Mathematical communication is an integral part of collaborative word problem solving [48], allowing students to express their mathematical reasoning in tasks that integrate CSCL [37]. The frequencies of the MM1 and MM2 learning scenario elements are consistent with findings from Anderson-Pence and Moyer-Packenham's [49] study on the relevance of students' collaborative work and mathematical communication in tasks that integrate VM. It is argued that these characteristics of the proposed learning scenario contributed to students being able to establish connections between mathematical concepts/knowledge and reality (MM3) and to solve real problems through a mathematical description (MM4).

To answer the second research question (what relationships exist between the constituent elements of the learning scenario?), the relationships identified between the occurrences of elements of the learning scenario regarding their proximity and co-occurrence are discussed.

From the analysis of the results, a close relationship emerged between the elements of the learning scenario MM1, MM2, MM4, CR2, VM2, and CL2. For a collaborative construction (MM1 and CL2) of a solution to a real problem (MM4) [27] to take place, students must be able to express their reasoning and mathematical ideas (MM2) [48]. The design of the learning scenario, in which the chosen VMs enable the visualisation of mathematical concepts (VM2), predicted that the idealised tasks, by integrating CSCL, would be conducive to the occurrence of CL2 and CR2 [38]. Regulation of learning in collaborative learning situations is multifaceted, implying complex interactions between the various actors. For co-regulation of learning (CR1 and CR2) to occur, each of the actors needs to be able to regulate their motivations, behaviours, emotions, and cognitive processes (SR); these interactions include the decisions made by teachers (S2) [39]. As such, the close relationships between the CR1, CR2, SR, and S2 codes are consistent with the literature.

A close relationship was also identified between students' co-regulation of learning (CR2) and the elements of the learning scenario that constitute the VM category. By providing immediate feedback (VM1), allowing visualisation of mathematical concepts (VM2), and posing and testing mathematical hypotheses (VM4), they promote students autonomous work [20]. These features of VMs also create opportunities for the teacher to help students establish mathematical connections (VM3) [19], allowing students to develop comprehension of mathematical concepts [26] conditions conducive to the occurrence of CR2.

As argued above, mathematical communication (MM2) is instrumental to the constituents of the learning scenario. As such, the co-occurrence of this element of the learning scenario with most of the others was expected-except for VM3, MG2, CR1, and SR-since the mathematical communication of the PST was not analysed. The co-occurrence of the learning scenario elements belonging to the MM category (MM1, MM2, MM3, and MM4) is consistent with the simplified modelling cycle presented by Ferri [27]: (1) understanding the task, (2) searching mathematics, (3) using mathematics, and (4) explaining mathematics. Even though the data do not allow identifying patterns of sequences of the codes, it is 
argued that the co-occurrence of MM1 and MM2 is transversal to the four stages of the simplified modelling cycle; the co-occurrence of MM2/MM3, MM2/MM4, and of MM3/MM4 falls within that predicted for stages 3 and 4 of the simplified modelling cycle. In the specific case of the proposed learning scenario, the first three stages correspond to the resolution of the task and the fourth to its discussion.

The co-occurrence of the learning scenario elements MM2, MM1, CR2, and CL2 is supported by the literature. As pointed above, mathematical communication (MM2) is necessary for students to express their mathematical reasoning and ideas in CSCL [37], contributing - in the specific circumstances of the proposed learning scenario- to the occurrence of CL2 and CR2 [38].

Regarding the co-occurrence pattern MM2/MM3, MM2/MM4, and MM2/CL1, the first two have already been justified. Concerning the co-occurrence of MM2/CL1, the PST should be able to help students make connections between mathematical and nonmathematical concepts and find solutions to the problems posed (CL1) $[27,29]$. For this to happen, students must be able to express their mathematical reasoning and ideas (MM2) [37,48].

Finally, regarding the most significant pattern of co-occurrences concerning the category VM-VM2/MM1, VM2/CL2, and VM2/CR2—it is argued that by allowing visualising mathematical concepts, hence reducing abstraction, this feature of VMs facilitates the comprehension of the mathematical concepts involved [22,23], promoting the occurrences of CL2 and CR2 [38], in the context established by the proposed learning scenario.

The results show that the elements of the learning scenario related to the PST actions present a low frequency. This is considered to be influenced by two factors: these relate to teaching competencies that require time and practice to develop [50], and the context of the learning scenario refers to the systematization and remediation of learning.

\section{Conclusions}

This study identified the characteristics of the learning scenario with the greatest influence on its structure: mathematical communication, collaborative learning, self-regulation, and co-regulation of learning. The action planned for the PST, the conditions conducive to students' autonomy, and the way technology was integrated into the design and implementation of the learning scenario contributed to the improvement of students' comprehension of the meanings of subtraction.

The results presented suggest that differentiated instruction, minimal guidance, and scaffolding may be important for students to be able to make mathematical connections between the manipulation and their interpretations of the representations offered by VM. While these results may be conditioned by the PST developing skills, it is hoped that they can contribute to the discussion concerning how teachers should provide support to students in activities that integrate VM. Future work that includes multiple teachers and addresses multiple interventions may allow us to seek to understand whether the characteristics of the learning scenario identified represent statistically significant variables for student learning.

Considering the current prevalence of touchscreens in the daily lives of students at the first-year elementary school, it would be relevant to understand the potential of replacing computers with tablets in this proposed learning scenario, as well as adding an interactive whiteboard that students can use to support their arguments during task discussion.

Author Contributions: Conceptualization, R.S., F.M. and C.C.; methodology, F.M., C.C. and J.C.; validation J.C. and J.B.L.; formal analysis, R.S., F.M. and J.C.; investigation, R.S.; data curation, J.C.; writing-original draft preparation, R.S., F.M. and C.C.; writing-review and editing, J.B.L.; supervision, C.C. and J.B.L.; funding acquisition, R.S., C.C., J.C. and J.B.L. All authors have read and agreed to the published version of the manuscript.

Funding: This research was funded by FCT/MCTES through national funds and when applicable co-funded EU funds under the project UIDB/50008/2020 (IT). This work was financially supported by National Funds through FCT - Fundação para a Ciência e a Tecnologia, I.P., under the project 
UIDB/00194/2020 (CIDTFF), as well as under the doctoral scholarship 2020.06821.BD. The APC was funded by CIDTFF.

Institutional Review Board Statement: Ethical review and approval were waived for this study, due to data protection being assured by following the institutional protocol in place that regulates the practice component of PST training, including data collection procedures.

Informed Consent Statement: Informed consent was obtained from all participants by a form that was delivered to children's legal guardians.

Conflicts of Interest: The authors declare no conflict of interest. The funders had no role in the design of the study; in the collection, analysis, or interpretation of data; in the writing of the manuscript; or in the decision to publish the results.

\section{Appendix A}

Table A1. Code frequency.

\begin{tabular}{ccccc}
\hline Dimensions of Analysis & Categories & Code & Code & \% Code \\
\hline RA & DI & DI1 & 0 & 0.00 \\
& DI & DI2 & 2 & 1.30 \\
& MG & MG1 & 2 & 1.30 \\
& MG & MG2 & 2 & 1.30 \\
& S & S1 & 0 & 0.00 \\
MC & S2 & 4 & 2.60 \\
& & 1 & 0.65 \\
& CL & CL1 & 3 & 1.95 \\
& CL2 & 9 & 5.84 \\
& CR & CR1 & 4 & 6.49 \\
& CR & CR2 & 22 & 14.60 \\
& VM & VM1 & 6 & 3.90 \\
VM & VM2 & 23 & 14.94 \\
& VM & VM3 & 1 & 0.65 \\
& VM & VM4 & 5 & 3.25 \\
MM & MM1 & 15 & 9.74 \\
MM & MM2 & 34 & 22.08 \\
MM & MM3 & 4 & 2.60 \\
MM & MM4 & 7 & 4.55 \\
& & Sum & 154.00 & 100.00 \\
\hline
\end{tabular}

\section{Appendix B}

Table A2. Code proximity matrix.

\begin{tabular}{|c|c|c|c|c|c|c|c|c|c|c|c|c|c|c|c|c|c|c|c|c|}
\hline Codes & MM4 & MM3 & MM2 & MM1 & VM4 & VM3 & VM2 & VM1 & CR2 & CR1 & $S R$ & $C L 2$ & CL1 & $M C$ & $S 2$ & S1 & \multicolumn{2}{|c|}{ MG2MG1 } & $D I 2$ & DI1 \\
\hline MM4 & 0 & 6 & 17 & 11 & 6 & 0 & 10 & 8 & 16 & 4 & 7 & 4 & 2 & 0 & 4 & 0 & 2 & 2 & 0 & 0 \\
\hline MM3 & 6 & 0 & 10 & 5 & 5 & 0 & 4 & 2 & 6 & 2 & 2 & 2 & 4 & 0 & 2 & 0 & 2 & 0 & 0 & 0 \\
\hline MM2 & 17 & 10 & 0 & 37 & 12 & 0 & 28 & 12 & 40 & 7 & 9 & 21 & 11 & 2 & 9 & 0 & 4 & 5 & 2 & 0 \\
\hline MM1 & 11 & 5 & 37 & 0 & 7 & 0 & 23 & 8 & 29 & 7 & 6 & 15 & 2 & 0 & 9 & 0 & 4 & 5 & 2 & 0 \\
\hline VM4 & 6 & 5 & 12 & 7 & 0 & 0 & 7 & 4 & 10 & 4 & 6 & 3 & 0 & 0 & 6 & 0 & 4 & 2 & 0 & 0 \\
\hline VM3 & 0 & 0 & 0 & 0 & 0 & 0 & 3 & 2 & 0 & 0 & 2 & 2 & 2 & 2 & 2 & 0 & 0 & 2 & 0 & 0 \\
\hline VM2 & 10 & 4 & 28 & 23 & 7 & 3 & 0 & 18 & 35 & 7 & 14 & 22 & 4 & 2 & 9 & 0 & 3 & 6 & 3 & 0 \\
\hline VM1 & 8 & 2 & 12 & 8 & 4 & 2 & 18 & 0 & 9 & 4 & 10 & 9 & 2 & 0 & 6 & 0 & 2 & 4 & 0 & 0 \\
\hline CR2 & 16 & 6 & 40 & 29 & 10 & 0 & 35 & 9 & 0 & 8 & 8 & 18 & 0 & 0 & 6 & 0 & 3 & 3 & 3 & 0 \\
\hline$C R 1$ & 4 & 2 & 7 & 7 & 4 & 0 & 7 & 4 & 8 & 0 & 6 & 4 & 2 & 0 & 6 & 0 & 2 & 4 & 0 & 0 \\
\hline$S R$ & 7 & 2 & 9 & 6 & 6 & 2 & 14 & 10 & 8 & 6 & 0 & 5 & 2 & 0 & 6 & 0 & 2 & 4 & 0 & 0 \\
\hline$C L 2$ & 4 & 2 & 21 & 15 & 3 & 2 & 22 & 9 & 18 & 4 & 5 & 0 & 3 & 0 & 3 & 0 & 0 & 3 & 2 & 0 \\
\hline CL1 & 2 & 4 & 11 & 2 & 0 & 2 & 4 & 2 & 0 & 2 & 2 & 3 & 0 & 2 & 2 & 0 & 0 & 2 & 2 & 0 \\
\hline$M C$ & 0 & 0 & 2 & 0 & 0 & 2 & 2 & 0 & 0 & 0 & 0 & 0 & 2 & 0 & 2 & 0 & 0 & 2 & 0 & 0 \\
\hline S2 & 4 & 2 & 9 & 9 & 6 & 2 & 9 & 6 & 6 & 6 & 6 & 3 & 2 & 2 & 0 & 0 & 4 & 4 & 2 & 0 \\
\hline$S 1$ & 0 & 0 & 0 & 0 & 0 & 0 & 0 & 0 & 0 & 0 & 0 & 0 & 0 & 0 & 0 & 0 & 0 & 0 & 0 & 0 \\
\hline
\end{tabular}


Table A2. Cont.

\begin{tabular}{|c|c|c|c|c|c|c|c|c|c|c|c|c|c|c|c|c|c|c|c|}
\hline Codes & MM4 & MM3 & MM2 & MM1 & VM4 & VM3 & VM2 & VM1 & CR2 & CR1 & $S R$ & $C L 2$ & $C L 1$ & $M C$ & S2 & S1 & MG2MG1 & DI2 & DI1 \\
\hline MG2 & 2 & 2 & 4 & 4 & 4 & 0 & 3 & 2 & 3 & 2 & 2 & 0 & 0 & 0 & 4 & 0 & 0 & 0 & 0 \\
\hline MG1 & 2 & 0 & 5 & 5 & 2 & 2 & 6 & 4 & 3 & 4 & 4 & 3 & 2 & 2 & 4 & 0 & 0 & 2 & 0 \\
\hline DI2 & 0 & 0 & 2 & 2 & 0 & 0 & 3 & 0 & 3 & 0 & 0 & 2 & 2 & 0 & 2 & 0 & 0 & 0 & 0 \\
\hline DI1 & 0 & 0 & 0 & 0 & 0 & 0 & 0 & 0 & 0 & 0 & 0 & 0 & 0 & 0 & 0 & 0 & 0 & 0 & 0 \\
\hline
\end{tabular}

\section{Appendix C}

Table A3. Code co-occurrence matrix.

\begin{tabular}{|c|c|c|c|c|c|c|c|c|c|c|c|c|c|c|c|c|c|c|c|c|}
\hline Codes & MM4 & MM3 & MM2 & MM1 & VM4 & VM3 & VM2 & VM1 & $C R 2$ & CR1 & $S R$ & $C L 2$ & CL1 & $M C$ & S2 & S1 & \multicolumn{2}{|c|}{ MG2MG1 } & DI2 & DI1 \\
\hline MM4 & 0 & 2 & 7 & 2 & 0 & 0 & 0 & 0 & 1 & 0 & 0 & 0 & 1 & 0 & 0 & 0 & 0 & 0 & 0 & 0 \\
\hline MM3 & 2 & 0 & 3 & 0 & 0 & 0 & 0 & 0 & 1 & 0 & 0 & 0 & 1 & 0 & 0 & 0 & 0 & 0 & 0 & 0 \\
\hline MM2 & 7 & 3 & 0 & 18 & 2 & 0 & 0 & 2 & 13 & 0 & 0 & 9 & 7 & 1 & 1 & 0 & 0 & 1 & 0 & 0 \\
\hline MM1 & 2 & 0 & 18 & 0 & 2 & 0 & 4 & 1 & 11 & 1 & 0 & 5 & 0 & 0 & 0 & 0 & 0 & 0 & 0 & 0 \\
\hline$V M 4$ & 0 & 0 & 2 & 2 & 0 & 0 & 0 & 1 & 1 & 1 & 0 & 1 & 0 & 0 & 0 & 0 & 0 & 0 & 0 & 0 \\
\hline VM3 & 0 & 0 & 0 & 0 & 0 & 0 & 1 & 0 & 0 & 0 & 0 & 0 & 1 & 0 & 1 & 0 & 0 & 1 & 0 & 0 \\
\hline VM2 & 0 & 0 & 0 & 4 & 0 & 1 & 0 & 1 & 3 & 0 & 1 & 3 & 1 & 0 & 1 & 0 & 0 & 1 & 0 & 0 \\
\hline VM1 & 0 & 0 & 2 & 1 & 1 & 0 & 1 & 0 & 2 & 0 & 1 & 2 & 0 & 0 & 0 & 0 & 0 & 0 & 0 & 0 \\
\hline$C R 2$ & 1 & 1 & 13 & 11 & 1 & 0 & 3 & 2 & 0 & 1 & 0 & 6 & 0 & 0 & 0 & 0 & 0 & 0 & 0 & 0 \\
\hline CR1 & 0 & 0 & 0 & 1 & 1 & 0 & 0 & 0 & 1 & 0 & 0 & 0 & 0 & 0 & 1 & 0 & 1 & 0 & 0 & 0 \\
\hline$S R$ & 0 & 0 & 0 & 0 & 0 & 0 & 1 & 1 & 0 & 0 & 0 & 1 & 0 & 0 & 0 & 0 & 0 & 0 & 0 & 0 \\
\hline$C L 2$ & 0 & 0 & 9 & 5 & 1 & 0 & 3 & 2 & 6 & 0 & 1 & 0 & 0 & 0 & 0 & 0 & 0 & 0 & 0 & 0 \\
\hline CL1 & 1 & 1 & 7 & 0 & 0 & 1 & 1 & 0 & 0 & 0 & 0 & 0 & 0 & 1 & 1 & 0 & 0 & 1 & 0 & 0 \\
\hline$M C$ & 0 & 0 & 1 & 0 & 0 & 0 & 0 & 0 & 0 & 0 & 0 & 0 & 1 & 0 & 1 & 0 & 0 & 1 & 0 & 0 \\
\hline$S 2$ & 0 & 0 & 1 & 0 & 0 & 1 & 1 & 0 & 0 & 1 & 0 & 0 & 1 & 1 & 0 & 0 & 2 & 2 & 0 & 0 \\
\hline S1 & 0 & 0 & 0 & 0 & 0 & 0 & 0 & 0 & 0 & 0 & 0 & 0 & 0 & 0 & 0 & 0 & 0 & 0 & 0 & 0 \\
\hline MG2 & 0 & 0 & 0 & 0 & 0 & 0 & 0 & 0 & 0 & 1 & 0 & 0 & 0 & 0 & 2 & 0 & 0 & 0 & 0 & 0 \\
\hline MG1 & 0 & 0 & 1 & 0 & 0 & 1 & 1 & 0 & 0 & 0 & 0 & 0 & 1 & 1 & 2 & 0 & 0 & 0 & 0 & 0 \\
\hline DI2 & 0 & 0 & 0 & 0 & 0 & 0 & 0 & 0 & 0 & 0 & 0 & 0 & 0 & 0 & 0 & 0 & 0 & 0 & 0 & 0 \\
\hline DI1 & 0 & 0 & 0 & 0 & 0 & 0 & 0 & 0 & 0 & 0 & 0 & 0 & 0 & 0 & 0 & 0 & 0 & 0 & 0 & 0 \\
\hline
\end{tabular}

\section{References}

1. Assunção Flores, M.; Gago, M. Teacher education in times of COVID-19 pandemic in Portugal: National, institutional and pedagogical responses. J. Educ. Teach. 2020, 46, 507-516. [CrossRef]

2. OECD. Education Policy Outlook 2019: Working Together to Help Students Achieve their Potential; OECD Publishing: Paris, France, 2019.

3. Prensky, M. Digital Natives, Digital Immigrants Part 1. Horizon 2001, 5, 1-6. [CrossRef]

4. Tabach, M.; Trgalová, J. The Knowledge and Skills that Mathematics Teachers Need for ICT Integration: The Issue of Standards. In Technology in Mathematics Teaching; Springer: Cham, Switzerland, 2019; pp. 183-203.

5. NCTM. Principles to Actions: Ensuring Mathematical Success for All; National Council of Teachers of Mathematics, Inc.: Reston, VA, USA, 2014; ISBN 0873537742.

6. Hegedus, S.; Laborde, C.; Brady, C.; Dalton, S.; Siller, H.-S.; Tabach, M.; Trgalova, J.; Moreno-Armella, L. Uses of Technology in Upper Secondary Mathematics Education; ICME-13 Topical Surveys; Springer International Publishing: Cham, Switzerland, 2017; Volume 2018, ISBN 978-3-319-42610-5.

7. Koehler, M.J.; Mishra, P. What is technological pedagogical content knowledge? Contemporary Issues in Technology and Teacher Education. Contemp. Issues Technol. Teach. Educ. 2009, 9, 60-70.

8. Drijvers, P. Selected Regular Lectures from the 12th International Congress on Mathematical Education; Springer: Cham, Switzerland, 2015; pp. 135-151.

9. Huang, R.; Zbiek, R.M. Prospective Secondary Mathematics Teacher Preparation and Technology. In The Mathematics Education of Prospective Secondary Teachers Around the World; Springer International Publishing: Cham, Switzerland, 2017; pp. 17-23, ISBN 978-3-319-38965-3.

10. Pedro, A.; Piedade, J.; Matos, J.F.; Pedro, N. Redesigning initial teacher's education practices with learning scenarios. Int. J. Inf. Learn. Technol. 2019, 36, 266-283. [CrossRef]

11. Matos, J.F. Princípios Orientadores para o Design de Cenários de Aprendizagem; Instituto de Educação: Lisboa, Portugal, 2014; ISBN 0021-9967. (Print) r0021-9967 (Linking).

12. Carroll, J.M. Five reasons for scenario-based design. Proc. Hawaii Int. Conf. Syst. Sci. 1999, 123, 1-11. [CrossRef]

13. Clements, D.H.; Sarama, J. Learning and Teaching Early Math, 3rd ed.; Routledge: New York, NY, USA, 2020; ISBN 9781003083528.

14. Carpenter, T.P.; Moser, J.M. The Acquisition of Addition and Subtraction Concepts in Grades One through Three. J. Res. Math. Educ. 1984, 15, 179-202. [CrossRef] 
15. Karatas, I.; Baki, A. The effect of learning environments based on problem solving on students' achievements of problem solving. Int. Electron. J. Elem. Educ. 2013, 5, 249-267.

16. Sarama, J.; Clements, D.H. Physical and Virtual Manipulatives: What Is "Concrete"? In International Perspectives on Teaching and Learning Mathematics with Virtual Manipulatives; Moyer-Packenham, P., Ed.; Springer: Cham, Switzerland, 2016 ; pp. 71-93.

17. Milner-Bolotin, M. Nurturing Creativity in Future Mathematics Teachers Through Embracing Technology and Failure. In Creativity and Technology in Mathematics Education; Freiman, V., Tassell, J., Eds.; Springer: Cham, Switzerland, 2018 ; pp. 251-278.

18. Moyer-Packenham, P.S.; Bolyard, J.J. Revisiting the Definition of a Virtual Manipulative. In International Perspectives on Teaching and Learning Mathematics with Virtual Manipulatives; Springer: Cham, Switzerland, 2016.

19. Bartolini, M.G.; Martignone, F. Manipulatives in Mathematics Education. In Encyclopedia of Mathematics Education; Springer International Publishing: Cham, Switzerland, 2020; pp. 487-494.

20. Suh, J.M. Ambitious Teaching: Designing Practice-Based Assignments for Integrating Virtual Manipulatives into Mathematics Lessons. In International Perspectives on Teaching and Learning Mathematics with Virtual Manipulatives; Springer: Cham, Switzerland, 2016.

21. Suh, J.; Moyer, P.S.; Heo, H.J. Examining technology uses in the classroom: Developing fraction sense using virtual manipulative concept tutorials. J. Interact. Online Learn. 2005, 3, 1-21.

22. Lin, C.P.; Shao, Y.J.; Wong, L.H.; Li, Y.J.; Niramitranon, J. The impact of using synchronous collaborative virtual tangram in children's geometric. Turk. Online J. Educ. Technol. 2011, 10, 250-258.

23. Moyer-Packenham, P.S.; Ulmer, L.A.; Anderson, K.L. Examining pictorial models and virtual manipulatives for third-grade fraction instruction. J. Interact. Online Learn. 2012, 11, 103-120.

24. Suh, J.M.; Moyer-Packenham, P.S. How Affordances and Constraints of Physical and Virtual Manipulatives Support the Development of Procedural Fluency and Algorithmic Thinking in Mathematics. Int. J. Res. Math. Educ. 2016, 6, $245-256$.

25. Shih, W.C. Enhancing virtual manipulatives for after-school tutoring in the subtraction unit. In Lecture Notes in Electrical Engineering; Springer: Berlin, Germany, 2015.

26. Pead, D.; Ralph, B.; Muller, E. Uses of Technologies in Learning Mathematics through Modelling. In Modelling and Applications in Mathematics Education; Blum, W., Galbraith, P.L., Henn, H.W., Niss, M., Eds.; Springer: Boston, MA, USA, 2007 ; pp. $309-318$.

27. Borromeo Ferri, R. Theoretical Competency: For Your Practical Work. In Learning How to Teach Mathematical Modeling in School and Teacher Education; Springer International Publishing: Cham, Switzerland, 2018; pp. 13-39.

28. Blum, W. Quality Teaching of Mathematical Modelling: What Do We Know, What Can We Do? In Proceedings of the 12th International Congress on Mathematical Education, Seoul, Korea, 15-18 July 2012; Springer International Publishing: Cham, Switzerland, 2015; pp. 73-96.

29. Kaiser, G. Mathematical Modelling and Applications in Education. In Encyclopedia of Mathematics Education; Lerman, S., Ed.; Springer International Publishing: Cham, Switzerland, 2020; pp. 553-561.

30. Bonotto, C. Engaging Students in Mathematical Modelling and Problem Posing Activities. J. Math. Model. Appl. 2010, 1, 18-32.

31. Silva, R. Modelação Matemática Como Ambiente de Aprendizagem: O Uso de Manipulativos Virtuais No Desenvolvimento dos Sentidos da Adição e da Subtração; Instituto Politécnico de Coimbra: Coimbra, Portugal, 2018.

32. Silva, R.; Martins, F.; Rato, V.; Raimundo, I. TPACK: Uma proposta de integração da tecnologia na aula de matemática. Exedra Rev. Cient. 2019, 1, 167-181.

33. Pratas, R.; Martins, F.; Rato, V. Modelação matemática como prática de sala de aula: O uso de manipulativos virtuais no desenvolvimento dos sentidos da adição. In Proceedings of the Atas do EIEM 2016, Encontro em Investigação em Educação Matemática, Évora, Portugal, 19-20 November 2016; Canavarro, A., Borralho, A., Brocardo, J., Santos, L., Eds.; SPIEM: Évora, Portugal, 2016; pp. 35-48.

34. Silva, R.; Costa, C.; Martins, F. Using Mathematical Modelling and Virtual Manipulatives to Teach Elementary Mathematics. In Technology and Innovation in Learning, Teaching and Education; Reis, A., Barroso, J., Lopes, J.B., Mikropoulos, T., Fan, C.W., Eds.; Springer: Cham, Switzerland, 2021; pp. 75-89.

35. Osana, H.P.; Duponsel, N. Manipulatives, Diagrams, and Mathematics: A Framework for Future Research on Virtual Manipulatives. In International Perspectives on Teaching and Learning Mathematics with Virtual Manipulatives; Moyer-Packenham, P.S., Ed.; Springer International Publishing: Cham, Switzerland, 2016; pp. 95-120, ISBN 978-3-319-32718-1.

36. Bardin, L. Análise de Conteúdo. São Paulo Edições 2016, 70, 279.

37. Chan, T.-W.; Kong, S.C.; Cheng, H.N.H. Learning Environments in Mathematics Education. In Encyclopedia of Mathematics Education; Lerman, S., Ed.; Springer International Publishing: Cham, Switzerland, 2020; pp. 459-464, ISBN 978-3-030-15789-0.

38. Chan, C.K.K. Co-regulation of learning in computer-supported collaborative learning environments: A discussion. Metacogn. Learn. 2012, 7, 63-73. [CrossRef]

39. Hadwin, A.; Järvelä, S.; Miller, M. Self-Regulated, Co-Regulated, and Socially Shared Regulation of Learning. In Handbook of Self-Regulation of Learning and Performance; Schunk, D.H., Greene, J.A., Eds.; Routledge: New York, NY, USA, 2017 ; pp. 83-106.

40. Amiel, T.; Reeves, T.C. Design-based research and educational technology: Rethinking technology and the research agenda. Educ. Technol. Soc. 2008, 11, 29-40.

41. Hofer, M.; Harris, J. Developing TPACK with Learning Activity Types. In The TPACK Handbook for Practitioners: Media Rich Cases about Teacher Knowledge; Hofer, M., Bell, L., Bull, G., Eds.; Association for the Advancement of Computers in Education: Waynesville, NC, USA, 2015; pp. 7-14, ISBN 978-1-939797-17-9. 
42. van den Bogaart, T.; Drijvers, P.; Tolboom, J. Co-Design and Use of Open Online Materials for Mathematics and Science Didactics Courses in Teacher Education: Product and Process. In Technology in Mathematics Teaching; Springer: Cham, Switzerland, 2019; pp. 205-222.

43. Vygotsky, L.S. Mind and Society: The Development of Higher Psychological Processes; Harvard University Press: Cambridge, MA, USA, 1978; ISBN 0674576292.

44. Dillenbourg, P.; Järvelä, S.; Fischer, F. The Evolution of Research on Computer-Supported Collaborative Learning. In TechnologyEnhanced Learning: Principles and Products; Balacheff, N., Ludvigsen, S., de Jong, T., Lazonder, A., Barnes, S., Eds.; Springer: Dordrecht, The Netherlands, 2009; pp. 3-19, ISBN 978-1-4020-9827-7.

45. Herrington, J.; Reeves, T.C.; Oliver, R. Authentic Learning Environments. In Handbook of Research on Educational Communications and Technology; Spector, J.M., Merrill, M.D., Elen, J., Bishop, M.J., Eds.; Springer: New York, NY, USA, 2014; pp. 401-412, ISBN 978-1-4614-3185-5.

46. Kuckartz, U.; Rädiker, S. Introduction: Analyzing Qualitative Data with Software. In Analyzing Qualitative Data with MAXQDA: Text, Audio, and Video; Springer International Publishing: Cham, Switzerland, 2019; pp. 1-11, ISBN 978-3-030-15671-8.

47. Durmuş, S.; Karakirik, E. Virtual Manipulatives in Mathematics Education-Research Paper. Turk. Online J. Educ. Technol. 2006, $5,117-123$.

48. Santos-Trigo, M. Problem-Solving in Mathematics Education. In Encyclopedia of Mathematics Education; Lerman, S., Ed.; Springer International Publishing: Cham, Switzerland, 2020; pp. 686-693, ISBN 978-3-030-15789-0.

49. Anderson-Pence, K.; Moyer-Packenham, P.S. Using Virtual Manipulatives to Enhance Collaborative Discourse in Mathematics Instruction. In Proceedings of the Annual Meeting of the American Educational Research Association (AERA), Chicago, IL, USA, 16-20 April 2015.

50. Linder, S.M.; Simpson, A. Towards an understanding of early childhood mathematics education: A systematic review of the literature focusing on practicing and prospective teachers. Contemp. Issues Early Child. 2018, 19, 274-296. [CrossRef] 